\title{
Bentonite Alteration due to Thermal-Hydro-Chemical Processes during the Early Thermal Period in a Nuclear Waste Repository
}

\author{
TIANFU XU ${ }^{1,3}$, RAINER SENGER ${ }^{2}$, AND STEFAN FINSTERLE ${ }^{1}$ \\ ${ }^{1}$ Earth Sciences Division, Lawrence Berkeley National Laboratory, Berkeley, CA 94720, \\ USA \\ ${ }^{2}$ INTERA Inc. Swiss Branch, Schloesslistrasse 12, CH-5408 Ennetbaden, Switzerland \\ ${ }^{3}$ School of Environment and Resources, University of Jilin, Jilin 130026, China
}

\begin{abstract}
After closure of an underground nuclear waste repository, the decay of radionuclides will raise temperature in the repository, and the bentonite buffer will resaturate by water inflow from the surrounding host rock. The perturbations from these thermal and hydrological processes are expected to dissipate within hundreds to a few thousand years. Here, we investigate coupled thermal-hydro-chemical processes and their effects on the short-term performance of a potential nuclear waste repository located in a clay formation. Using a simplified geometric configuration and abstracted hydraulic parameters of the clayey formation, we examine geochemical processes, coupled with thermo-hydrologic phenomena, and potential changes in porosity near the waste container during the early thermal period. The developed models were used for evaluating the mineral alterations and potential changes in porosity of the buffer, which can affect the repository performance. The results indicate that mineral alteration and associated changes in porosity induced by early thermal and hydrological processes are relatively small and are expected to not significantly affect flow and transport properties. Chlorite precipitation was obtained in all simulation cases. A maximum of one percent volume fraction of chlorite could be formed, whose process may reduce swelling and sorption capacity of bentonite clay, affecting the performance of the repository. llitisation process was not obtained from the present simulations.
\end{abstract}

Key words. Nuclear waste repository, Bentonite buffer, Mineral alteration, Reactive geochemistry.

\section{Introduction}

Bentonite is considered as buffer and backfill materials in many high-level waste (HLW) repository concepts. Its low permeability to minimize flow rate of percolating groundwater, micro-porous structure and good sorption (retardation) properties make this material an effective barrier to protect the canister and to restrict the movement of radionuclides released from the waste packages after canister failure (Ref. 1). These 
favorable properties, however, may be altered by thermally-induced effects that arise from the decay heat released from the waste.

Thermally-induced dissolution and precipitation of minerals at the bentonite buffer may change hydrologic properties such as porosity and permeability. Formation of new mineral phases may impact backfill performance by changing swelling and sorption behavior of the barrier, and then radionuclide release rates. When exposed to higher temperatures and pressures, the main constituting mineral of bentonite, smectite, may be unstable and transformed to more stable silicate phases, such as illite and chlorite (Ref. 2), reducing swelling and sorption capacity of the barrier. This transformation process is strongly affected by kinetic and hydrologic constraints, such as time, concentration of exchangeable cations, saturation state in the bentonite and permeability of the adjacent formation (Ref. 3). Furthermore, a potential decrease in permeability associated with mineral precipitation can affect the pressure buildup associated with gas generation from corrosion of the waste canister (Ref. 4). The generation, accumulation and release of gases from the disposal system may affect a number of processes that influence long-term radiological safety of the repository (Ref. 5).

Simulating coupled thermal-hydrological-chemical (THC) processes in the backfill material (bentonite buffer) and near-field environment of a heat-generating nuclear waste repository requires site-specific and detailed information to assess the coupled processes and their impact at any particular site, and to develop engineering designs. Before moving into site-specific investigations, we explore general features and issues representing characteristics that are common and essential for many such systems.

The present study is not related to any particular site. However, the geometric configuration and the hydraulic parameters and mineralogical composition of the clayey formation are abstracted from a nuclear waste repository concept considered in Switzerland (Ref. 6). The reference design for canisters to be stored in a repository for spent fuel and high-level waste (SF/HLW) involves a cast steel canister with about $20 \mathrm{~cm}$ wall thickness. The canisters are about $1 \mathrm{~m}$ in diameter and are surrounded by a $0.75-\mathrm{m}$ thick bentonite buffer in emplacement tunnels which are $2.5 \mathrm{~m}$ in diameter (Ref. 7). The individual waste canisters are as much as $4.8 \mathrm{~m}$ long and spaced at 3-m distances along a 700 m-long emplacement tunnel. The repository tunnel is assumed to be in the water- 
saturated zone at a depth of $650 \mathrm{~m}$ below the land surface in the host rock which is referred to as the Opalinus Clay.

The main objectives of this modeling work are to investigate thermally-induced mineral alteration and formation of new mineral phases, and their effects on changes of porosity at the bentonite buffer. The results may be useful for performance assessment of the bentonite buffer.

\section{Problem Setup}

\subsection{Thermal and hydrological conditions}

The present study employed a simplified model, which was previously used by Senger et al. (Ref. 4) and Xu et al (Ref. 8), and the dimensions are based on a waste canister and emplacement configuration of spent fuel and high-level waste as described in Ref. 7. The model is represented by a radially symmetric geometry, ignoring the lateral no-flow boundary and gravity effects (Fig. 1). The repository is located $650 \mathrm{~m}$ below the land surface. The Opalinus clay host rock is assumed to be initially fully water-saturated with a background pressure of 65 bar. The outer boundary at a radial distance of $75 \mathrm{~m}$ was set at a constant pressure of $65 \mathrm{bar}$ and a constant temperature of $38^{\circ} \mathrm{C}$.

The thermo-physical properties for bentonite buffer and Opalinus clay are summarized in Table 1. The van Genuchten model (Refs. 9 and 10) is used to describe the functional relationships between relative permeability and saturation, and capillary pressure and saturation for the different materials. The parameters were taken from Xu et al. (Ref. 8) and Senger and Ewing (Ref. 11). Senger and Ewing reported simulation results for a 3-D model of the thermo-hydrologic conditions in the vicinity of a backfilled SF emplacement tunnel. In their model, the spent fuel and high level waste (SF/HLW) disposal system was designed for a more comprehensive representation of the thermohydrological (TH) processes, which includes a detailed three-dimensional model of the SF/HLW configuration and a model for simulating the TH conditions during the operational period and early post-closure period which is dominated by thermal effects associated with heat generation from radioactive decay in SF and HLW. They quantified 
the coupled thermo-hydrologic evolution of temperature, saturation, and pressure to determine potential non-uniform resaturation of the bentonite buffer or potential localized accumulation of pore water in contact with the waste canister.

The heat generation of the SF and HLW canisters and the rate of its decrease with time due to radioactive decay depend on the type of waste. For the reference design, the length of spent fuel canister is a weighted average of the three canister types. For the case of spent fuel, some canisters contain only UO2 assemblies (BWR UO2, PWR UO2), while others contain both UO2 and MOX (mixed oxide) fuel assemblies (Ref. 12). It is assumed here that the initial heat output of UO2/MOX canisters is $1500 \mathrm{~W} /$ canister and decreasing slowly as a result of significantly higher Pu content, whereas for the HLW the initial heat output is $\sim 1220 \mathrm{~W}$ and decreases more rapidly, because of the low actinide content of HLW (Ref. 5).

For this study a variable temperature inner boundary, representing heat generation due to decay from the waste package, was developed using successive fixed heat capacity at the canister grid block. This heat boundary was specified such that a rough correspondence was obtained to the temperatures at the canister surface computed in the simulation of Senger and Ewing (Ref. 11). The temperature was set initially at $150^{\circ} \mathrm{C}$ at this grid block, and allowed to decrease through conductive heat transport into the bentonite buffer and surrounding host rock. The temperatures decreased from the initial $150^{\circ} \mathrm{C}$ to about $55^{\circ} \mathrm{C}$ after 1,000 years (Fig. 2). An initial temperature of $38^{\circ} \mathrm{C}$ was used for the remaining grid blocks of the model domain.

Many thermal and hydrological factors and parameters could affect the temperature evolution. In the 3-D modeling study of Senger and Ewing, the peak temperature varies. For low water content, the temperatures reach $173^{\circ} \mathrm{C}$ at the canister/buffer interface. For a case of high water content, the maximum temperature is about $60^{\circ} \mathrm{C}$. The initial $150^{\circ} \mathrm{C}$ chosen in the present modeling study is close to the high peak, which could provide an up-bounding condition for geochemical calculations. Temperature falling off took place mostly in the first 1,000 years. For sensitivity study, a simulation period of 10,000 years was also carried out. 


\subsection{Geochemical conditions}

The initial mineral composition of bentonite and Opalinus clay used in the present modeling is given in Table 2. The MX-80 type of bentonite is used for the buffer materials, containing 75\% montmorillonite- $\mathrm{Na}$ ( a substitute of smectite- $\mathrm{Na}$ in the modeling ), which is the dominant mineral. The mineral content of Opalinus clay was assigned based on that given in Ref. 13.

Two initial water chemical compositions were used: (1) a dilute water composition, and (2) a composition measured for the BWS-A6 water extracted from the host rock (Ref. 13). Prior to simulating reactive transport, batch geochemical modeling of water-rock interaction for the two materials was conducted, equilibrating the initial water with the primary minerals listed in Table 2 at a temperature of $38^{\circ} \mathrm{C}$. A reasonably short simulation time of 10 years is needed to obtain nearly steady-state aqueous solution compositions, which were then used as initial chemical conditions for reactive transport (THC) simulations.

\subsection{Reaction kinetics}

Reactive chemical-transport modeling requires not only a conceptual understanding of the mechanisms involved in the nucleation, precipitation, and dissolution of the suite of participating minerals, but also quantitative estimates of relevant kinetic parameters. In this work, a general form of rate expression was used, which is based on transition state theory (TST) (Refs. 14 and 15):

$$
r=k A\left[1-\left(\frac{Q}{K}\right)^{\theta}\right]^{\eta}
$$

where, $r$ is the kinetic rate (positive values indicate dissolution, and negative values precipitation), $k$ is the rate constant (moles per unit mineral surface area and unit time), 
which is temperature dependent, $A$ is the specific reactive surface area per $\mathrm{kg}_{2} \mathrm{O}, K$ is the equilibrium constant for the mineral-water reaction written for the dissolution of one mole of mineral, and $Q$ is the reaction quotient. The parameters $\theta$ and $\eta$ must be determined experimentally, but are commonly set equal to unity when experimental quantification is unavailable. The precipitation of secondary minerals is represented using the same kinetic expression as for dissolution.

For many minerals, the kinetic rate constant $k$ contains the summed effects from three mechanisms (Refs. 14 and 16):

$$
\begin{array}{r}
k=k_{n u}^{25} \exp \left[\frac{-E_{n u}}{R}\left(\frac{1}{T}-\frac{1}{298.15}\right)\right]+k_{H}^{25} \exp \left[\frac{-E_{H}}{R}\left(\frac{1}{T}-\frac{1}{298.15}\right)\right] a_{H}^{n_{H}} \\
+k_{O H}^{25} \exp \left[\frac{-E_{O H}}{R}\left(\frac{1}{T}-\frac{1}{298.15}\right)\right] a_{O H}^{n_{O H}}
\end{array}
$$

where subscripts $n u, H$, and $O H$ indicate neutral, acid, and base mechanisms, respectively, $E$ is the activation energy, $k^{25}$ is the rate constant at $25^{\circ} \mathrm{C}, R$ is the gas constant, $T$ is absolute temperature, $a$ is the activity of the species, and $n$ is a power term (constant). Notice that parameters $\theta$ and $\eta$ (see Eq. 1) are assumed to be the same for each mechanism, and are set to unity in the present work.

The kinetic rate of mineral dissolution and precipitation includes a product of the rate constant and reactive surface area as represented by Eq. 1. The parameters used for the kinetic rate expression are given in Table 3. Calcite and anhydrite are assumed to react rapidly (relative to the time frame being modeled), and thus an equilibrium model can be used. In Table 3, we include separate rate constants $\left(k^{25}\right)$, activation energies $(E)$, and reaction order $(n)$ for processes catalyzed by $\mathrm{H}^{+}$or $\mathrm{OH}^{-}$. At any $\mathrm{pH}$, the total rate is the sum of the rates from all three mechanisms. Catalysis by $\mathrm{H}^{+}$or $\mathrm{OH}^{-}$is considered only for mineral dissolution. Parameters for the rate law were taken from Ref. 16, who compiled and fitted experimental data reported by many investigators. Parameters for montmorillonite were set to those of smectite.

If the aqueous phase supersaturates with respect to a potential secondary mineral, a 
small volume faction of $1 \times 10^{-6}$ is used for calculating the seed surface area for the new phase to grow. The precipitation of secondary minerals is represented using the same kinetic expression as that for dissolution. However, because precipitation rate data for most minerals are unavailable, only the neutral mechanism with parameters given in Table 3 was employed to describe precipitation. Multiple kinetic precipitation mechanisms can be specified in an input file of the TOUGHREACT program (Ref. 17), should such information become available.

\subsection{Simulation Setup}

\section{Surface area simulations}

Mineral reactive-surface areas (the second column of Table 3) are based on the work of Sonnenthal et al. (Ref. 18) and Mukhopadhyay et al. (Ref. 19), and were calculated assuming that the rock framework consists of a cubic array of truncated spheres. The larger surface areas for clay minerals are due to smaller grain sizes. Mineral dissolution and precipitation rates are related to the product of the kinetic rate constant and reactive surface area, the magnitudes of which are highly uncertain and cover a wide range of values. Some other investigators reported that the surface areas of real smectite clay could be three orders of magnitude higher than those listed in Table 3 (Ref. 20). Therefore, a total of four simulations were performed. The first simulation used reactive surface areas given in Table 3, representing the reference case. Three more sensitivity simulations were performed by decreasing the surface area by one order of magnitude (Case 2), increasing by one order of magnitude (Case 3), and increasing by three orders of magnitude (Case 4).

\section{Additional simulations}

Decay heat time-dependence as shown in Fig. 2 is strongly dependent on the particular nuclear waste stream involved. In some cases, decay heat may fall off much more slowly. To reflect this, an additional simulation was performed for 10,000 years using a temperature profile similar to Fig. 2 but decreasing to $55^{\circ} \mathrm{C}$ in a time period of 10,000 years (instead of 1,000 years) by increasing the heat capacity. This simulation of 
longer period was based on Case 4, or the surface areas increased by three orders of magnitude. A final simulation considered cation exchange reactions using parameters given in Appendix A.

\subsection{Simulation Approach}

The present simulations employed the nonisothermal reactive geochemical transport code TOUGHREACT (Refs. 17 and 23). This code introduces reactive chemistry into the multiphase fluid and heat flow code TOUGH2 (Ref. 24). Interactions between mineral assemblages and fluids can occur under local equilibrium or kinetic rates. Precipitation and dissolution reactions can change formation porosity and permeability, and can also modify the unsaturated flow properties of the rock. A broad range of subsurface thermal-physical-chemical processes are considered under various thermo-hydrological and geochemical conditions of pressure, temperature, water saturation, ionic strength, and $\mathrm{pH}$ and Eh. Temporal changes in porosity and permeability due to mineral dissolution and precipitation can be considered in the model. Mineral dissolution and precipitation are considered under kinetic conditions. Changes in porosity are calculated from changes in mineral volume fractions. Permeability changes can then be evaluated by consideration of several alternative models describing the porositypermeability relationship, including a simple grain model of Kozeny-Carman, as used in the present study.

The TOUGH programs use integral finite differences for space discretization (IFD; Ref. 25). The IFD method provides for flexible discretization using irregular grids, which is well suited for simulation of flow, transport, and fluid-rock interaction in heterogeneous and fractured rock systems with varying petrology and complex model boundaries due to the presence of engineered structures. For regular grids, the IFD method is equivalent to the conventional finite difference method. An implicit timeweighting scheme is used for modeling flow, transport, and kinetic geochemical reactions. The program can be applied to one-, two-, or three-dimensional porous and fractured media with physical and chemical heterogeneity, and can accommodate any number of chemical species present in liquid, gas and solid phases. 
The program is run with different equation-of-state modules depending on the phases and components of interest. Here we use the EOS4 module to calculate the thermo-physical properties of the fluid mixture. In the EOS4 module, provision is made for vapor pressure lowering effects (see Ref. 24). Vapor pressure is expressed by Kelvin's equation, which is a function not only of temperature, but depends also on capillary pressure, which in turn is a function of saturation.

The swelling process of bentonite and clay is not considered in this paper, because the current simulation tool does not have this capability. The impact of clay swelling on porosity and related flow and transport properties could be important.

\section{Model Results}

\subsection{Surface Area Simulations}

After closure of an underground nuclear waste repository, the decay of radionuclides elevates temperatures in the waste canister and the surrouding buffer and host rock. The bentonite buffer resaturates by water inflow from the surrounding host rock. Near the waste canister the inflowing water can evaporate as the temperatures in the buffer exceed $100^{\circ} \mathrm{C}$. The perturbations from these thermal and hydrological processes induce mineral dissolution and precipitation. Consequently, porosity of the bentonite buffer is changed. The simulated porosity distribution at different times for different cases is presented in Fig. 3. For the first case (base-case), porosity decreases from the initial value of 0.475 to as low as 0.474 , indicating precipitation dominates. Changes in porosity are larger close to the interface between the bentonite buffer and Opalinus clay host rock because resaturation processes carry chemical constituents from the host rock. Decreases in porosity are smaller close to the canister surface, because water saturation remained low due to evaporation. Decreases in reactive surface area (and thus reaction rate) results in reductions in mineral alteration and less changes in porosity (compare Figs. 3a and 3b). Conversely, increases in reactive surface area causes increases in mineral alteration and porosity change (compare Figs. 3a to 3c and 3d). When surface area increases by three orders of magnitude, porosity decreases from the initial value of 0.475 to 0.472 (Fig. 3d). The more the increase in reactive surface area, the more the 
decrease in porosity. However, the rate of porosity decrease is less pronounced when the surface area is larger (compare Figs. 3c and 3d). Overall, no significant changes in porosity occur during the 1,000 year period of thermal and resaturation processes.

The porosity changes are caused by mineral dissolution and precipitation. When dissolution dominates among all minerals, porosity increases. In contrary, when precipitation dominants, porosity decreases. Montmorillonite-Na, with an initial volume fraction of 75\%, dissolves for all four cases. Fig. 4 shows changes in montmorillonite-Na volume fraction. Decreases in reactive surface area (or reaction rate) results in reduced montmorillonite-Na dissolution (compare Figs. 4a and 4b). Conversely, increases in reactive surface area (rate) causes increases in its dissolution (compare Figs. 4a and 4c). When reactive surface area increases by one order of magnitude, slightly lower than $2 \%$ volume fraction of montmorillonite-Na dissolves. Reactive surface area increased by three orders of magnitude results in about $2 \%$ volume fraction of montmorillonite- $\mathrm{Na}$ dissolution (Fig. 4d). Even though significant amounts of montmorillonite-Na dissolve, porosity still decreases especially close to the interface, because large amounts of Kfeldspar, kaolinite and chlorite precipitate (see Figs. 7-9, which will be discussed below).

The pattern of annite dissolution is similar to that of montmorillonite-Na (Fig. 5). Calcite precipitates in most parts of the bentonite because its solubility decreases with temperature, but it dissolves close to the interface with the host rock, supplying reactants for precipitation close to the hot canister surface (Fig. 6). Calcite dissolution and precipitation is not sensitive to a change in reactive surface area, because its reaction is much faster and controlled by reactant supply. K-feldspar precipitation occurs over the entire radial distance with increasing amounts of precipitate close to the host rock interface (Fig. 7). Maximum amount of K-feldspar precipitation for the cases of surface areas increased by one order of magnitude is similar to that by three orders of magnitude, or about $2 \%$ volume fraction close to the interface. Kaolinite precipitates within the entire bentonite buffer, with increasing rates towards the host rock interface (Fig. 8). The pattern of chlorite precipitation is the same as that for kaolinite (Fig. 9). 
Illitisation is a process of transformation of smectite (montmorrilonite used in the present modeling) to illite upon heating, which may lead to reduce swelling capacity and plasticity of the bentonite material (Ref. 1). No illite precipitation was obtained from the present simulations, because $\mathrm{K}^{+}$supply was limited and consumed by K-feldspar precipitation. Chloritisation, a process of converting smectite to chlorite, was obtained from the simulations. The process leads to reduction in swelling capacity and cation exchange capacity of the bentonite buffer. However, amounts of chlorite precipitation in the present simulations are not significant, with a maximum volume fraction of about $0.36 \%$ for the case of surface area increased by three orders of magnitude (Fig. 9d). A further potential pathway leading the conversion to chlorite is related to the corrosion of the steel canister and interaction of oxidized Fe species with the bentonite clay (Ref. 1). The corrosion of the steel canister is not considered in the current study, which should be incorporated into the model in the future.

\subsection{Additional simulations}

Changes in porosity, obtained from a simulation period of 10,000 years (for the case of decay heat falling off much more slowly), are given in Fig. 10. The porosity decreases to 0.466 (over 0.472 for Case 4 of 1000-year simulation that used the same surface areas, or increased by three orders of magnitude, see Fig. 3d). The porosity change is still not significant for this longer period of simulation. The mineral alteration pattern is similar to Case 4 . However, nearly $1 \%$ volume of chlorite precipitated close to the interface $(0.36 \%$ in Case 4$)$. The chloritisation process may reduce swelling and sorption capacity of bentonite clay. Illitisation process still did not occur.

When considering cation exchange, porosity mostly increases, but slightly decreases close to the interface with the host rock and does not change close to the canister surface (Fig. 11). Overall, no significant changes in porosity occur for the cation exchange case. 


\section{Summary and Conclusions}

A 1D radially symmetric model of a SF waste canister emplaced with bentonite buffer in a deep underground repository in the Opalinus clay has been developed, representing the essential general features and issues related to a nuclear waste repository. Using this model, mineral alteration and changes in porosity for the early thermal and resaturation processes in a waste repository for SF waste canisters were examined for different cases. The following conclusions can be drawn from the modeling analyses:

The perturbations from these thermal and hydrological processes result in a decrease in porosity, indicating precipitation dominates. Even though montmorriloniteNa with an initial volume fraction of $75 \%$ of the bentonite, dissolves for all simulation cases, the slight decrease in porosity is due to precipitation of K-feldspar, kaolonite, and chlorite. Decreases in porosity in the bentonite are larger close to the interface with the Opalinus clay host rock because resaturation processes carry chemical constituents from the host rock into the bentonite. Mineral alteration and changes in porosity are sensitive to reactive surface area, which strongly affects the kinetic reaction rates. Cation exchange indirectly affects mineral alteration, and thus has a second-order impact on porosity changes. Overall, mineral alteration and associated changes in porosity induced by early thermal and hydrological processes are relatively small and are expected to not significantly affect flow and transport properties.

Chlorite precipitation was obtained in all simulation cases. A maximum of one percent volume fraction of chlorite precipitated for a longer simulation period of 10,000 years using largest reactive surface area. Chloritisation process may reduce swelling and sorption capacity of bentonite clay, affecting the performance of the repository. A potential pathway leading the conversion to chlorite is related to the corrosion of the steel canister and interaction of oxidized Fe species with the bentonite. The corrosion of the steel canister should be incorporated into the model in the future. Illitisation process was not obtained from the present simulations, because $\mathrm{K}^{+}$supply was limited. 
The preliminary modeling presented here is for a simplified geometric configuration and abstracted hydraulic parameters and mineralogy of the clayey formation. However, this modeling and the sensitivity analyses were useful in identifying the role of some physical and chemical parameters in the alteration of the bentonite buffer materials. The developed model may provide a useful tool for gaining a better understanding of the coupled chemical and physical processes, as well as the controlling conditions and relevant parameters, for a site-specific repository system. 


\section{Appendix A Cation Exchange Parameters}

The Gaines-Thomas convention (Ref. 21) was used for cation exchange. In this convention, selectivities were calculated by using the equivalent fraction of the exchanged cations for the activity of the exchanged cations. It should be pointed out that selectivity is a relative concept. $\mathrm{Na}^{+}$was chosen as the reference. Therefore, $\mathrm{Na}^{+}$ selectivity is equal to one. According to this definition, a lower selectivity corresponds to a higher exchange capacity. A divalent cation, in general, is more strongly exchanged than a monovalent cation. Parameters used for cation exchange reactions are listed in Table 4, which were taken from Ref. 22. The cation exchange capacity (CEC) for bentonite was set to $105 \mathrm{meq} / 100 \mathrm{~g}$. The CEC for Opalinus Clay was assumed to be half of that of bentonite, or $52.5 \mathrm{meq} / 100 \mathrm{~g}$ 


\section{ACKNOWLEDGMENT}

This work was supported by the National Co-operative for the Disposal of Radioactive Waste (NAGRA) of Switzerland, and, in part, by the U.S. Dept. of Energy under Contract No. DE-AC02-05CH11231

\section{REFERENCES}

1. P. WERSIN, L.H. JOHNSON, and I.G. MCKINLEY, "Performance of the bentonite barrier at temperatures beyond $100{ }^{\circ} \mathrm{C}$ : A critical review," Physics and Chemistry of the Earth, 32, 780(2007).

2. A. INOUE, "Formation of clay minerals in hydrothermal environments." In: Velde, B. (Ed.), Origin and Mineralogy of Clays. Springer, pp. 268-329 (1995).

3. R. PUSCH, and F.T. MADSEN, "Aspects of the illitization of the Kinnekulle bentonites,” Clays Clay Miner, 43, 261(1995).

4. R. SENGER, P.M. MARSCHALL, and S. FINSTERLE, "Investigation of TwoPhase Flow Phenomena Associated with Corrosion in an SF/HLW Repository in Opalinus Clay, Switzerland," Physics and Chemistry of the Earth, 33, pS317-S326 (2008).

5. NEA , "Gas Generation and Migration in Radioactive Waste Disposal: SafetyRelevant Issues: Organisation for Economic Co-operation and Development,” ISBN 9264-18672-7, 192p (2001).

6. NAGRA, "Project Opalinus Clay: Safety Report. Demonstration of Disposal Feasibility (Entsorgungsnachweis) for Spent Fuel, Vitrified High-Level Waste and LongLived Intermediate-Level Waste," NAGRA Technical Report NTB 02-05, NAGRA, Wettingen, Switzerland (2002).

7. L.H. Johnson, M. Niemeyer, G. Klubertanz, P. Siegel, and P. Gribi, "Calculation of the temperature evolution of a repository for spent fuel, vitrified high-level waste and intermediate level waste in Opalinus Clay,” NAGRA Technical Report NTB 01-04. Nagra, Wettingen, Switzerland (2002).

8. T. XU, R. SENGER, and S. FINSTERLE, "Corrosion-induced Gas Generation in a Nuclear Waste Repository: Reactive Geochemistry and Multiphase Flow Effects,” Appl. Geochem., 23, 3423(2008).

9. M.Th. VAN GENUCHTEN, "A Closed-form Equation for Predicting the Hydraulic Conductivity of Unsaturated Soils,” Soil Sci. Soc. Am. J., 44, 892 (1980). 
10. Y. MUALEM, “A New Model for Predicting the Hydraulic Conductivity of Unsaturated Porous Media,” Water Resour. Res., 12, 513 (1976).

11. R. SENGER and J. EWING, "Evolution of Temperature and Water Content in the Bentonite Buffer: Detailed Modeling of Two-Phase Flow Processes Associated with the Early Closure Period - Complementary Simulations,” Report NAB 08-53 for NAGRA, INTERA Inc., Austin, Texas 78758 (2008).

12. L.H. Johnson, and F. King, "Canister options for the direct disposal of spent fuel, NAGRA Technical Report NTB 02-11,” NAGRA, Wettingen, Switzerland (2003).

13. R. FERNÁNDEZ, J. CUEVAS, L. SÁNCHEZ, R.V. DE LA VILLA, and S. LEGUEY, Reactivity of the Cement-bentonite Interface with Alkaline Solutions using Transport Cells, Appl. Geochem., 21, 977 (2006).

14. A. C. LASAGA, J.M. SOLER, J. GANOR, T.E. BURCH, and K.L. NAGY, "Chemical Weathering Rate Laws and Global Geochemical Cycles," Geochim. Cosmochim. Acta., 58, 2361 (1994).

15. C.I. STEEFEL and A.C. LASAGA, “A Coupled Model for Transport of Multiple Chemical Species and Kinetic Precipitation/dissolution Reactions with Applications to Reactive Flow in Single Phase Hydrothermal System,” Am. J. Sci., 294, 529 (1994).

16. J. PALANDRI, AND Y.K. KHARAKA, “A Compilation of Rate Parameters of Water-Mineral Interaction Kinetics for Application to Geochemical Modeling," US Geol. Surv. Open File Report 2004-1068, 64 pp (2004).

17. T. XU, E.L. SONNENTHAL, N. SPYCHER, and K. PRUESS, “TOUGHREACT: A Simulation Program for Non-Isothermal Multiphase Reactive Geochemical Transport in Variably Saturated Geologic Media,” Comput. Geosci., 32, 145 (2006).

18. E. SONNENTHAL, A. ITO, N. SPYCHER, M. YUI, J. APPS, Y. SUGITA, M. CONRAD, and S. KAWAKAMI, Approaches to Modeling Coupled Thermal, Hydrological, and Chemical Processes in the Drift Scale Heater Test at Yucca Mountain,” International Journal of Rock Mechanics and Mining Sciences, 42, 698 (2005).

19. S. MUKHOPADHYAY, E. SONNENTHAL, and N. SPYCHER, "Modeling of Coupled Heat Transfer and Reactive Transport Processes in Porous Media: Application to Seepage Studies at Yucca Mountain, Nevada.” Journal of Porous Media, 12, 725-748 (2009).

20. Y. PAUL-CHENG, S. YUN-HWEI, "Determination of the surface area of smectite in water by ethylene oxide chain adsorption," Journal of Colloid and Interface Science, 285, 443(2005) 
21. C.A.J. APPELO, "Cation and Proton Exchange, $\mathrm{pH}$ Variations and Carbonate Reactions in a Freshening Aquifer,” Water Resour. Res., 30, 2793 (1994).

22. JNC, "H12: Project to Establish the Scientific and Technical Basis for HLW Disposal in Japan,” TN1410 2000-001, JNC, Tokai-mura, Japan (2000).

23. T. $\mathrm{Xu}$, and K. Pruess, "Modeling Multiphase Non-isothermal Fluid Flow and Reactive Geochemical Transport in Variably Saturated Fractured Rocks: 1. Methodology,” Am. J. Sci., 301, 16 (2001).

24. K. PRUESS, C. OLDENBURG, and G. MORIDIS, “TOUGH2 User's Guide Version 2.0,” Report LBNL-43134, Lawrence Berkeley National Laboratory, Berkeley, California (1999).

25. T.N. NARASIMHAN, and P.A. WITHERSPOON, "An Integrated Finite Difference Method for Analyzing Fluid Flow in Porous Media,” Water Resour. Res., 12, 57 (1976). 


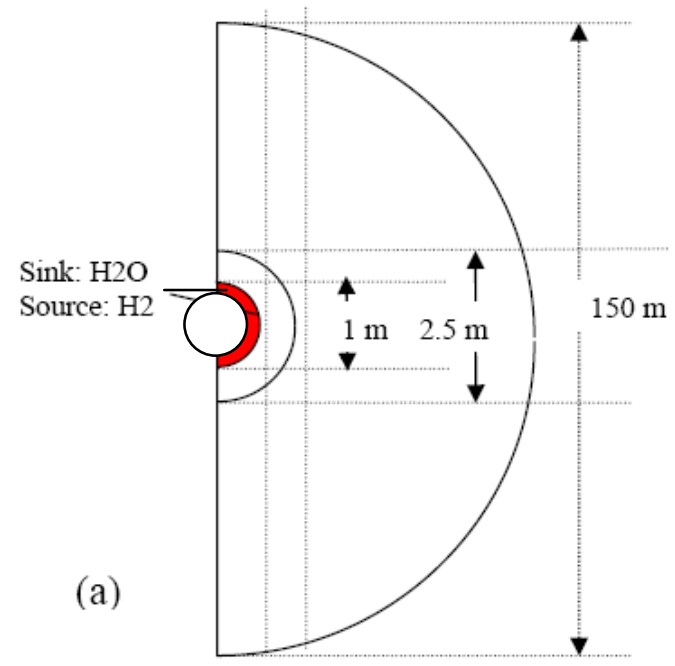

Fig. 1. Radially symmetric model, representing a single waste canister, canister hull, bentonite backfill, and the Opalinus clay host rock. 


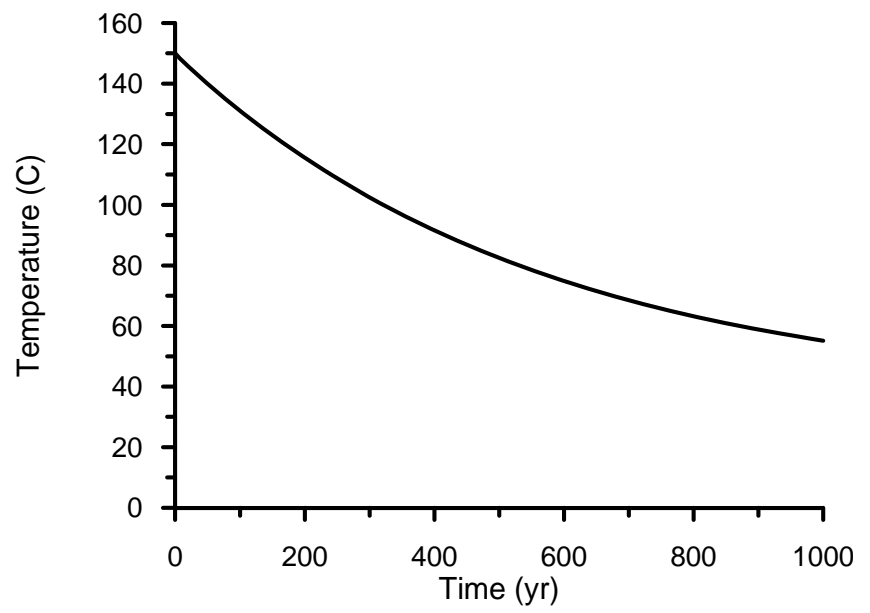

Fig. 2. Temperature evolution at the canister surface 

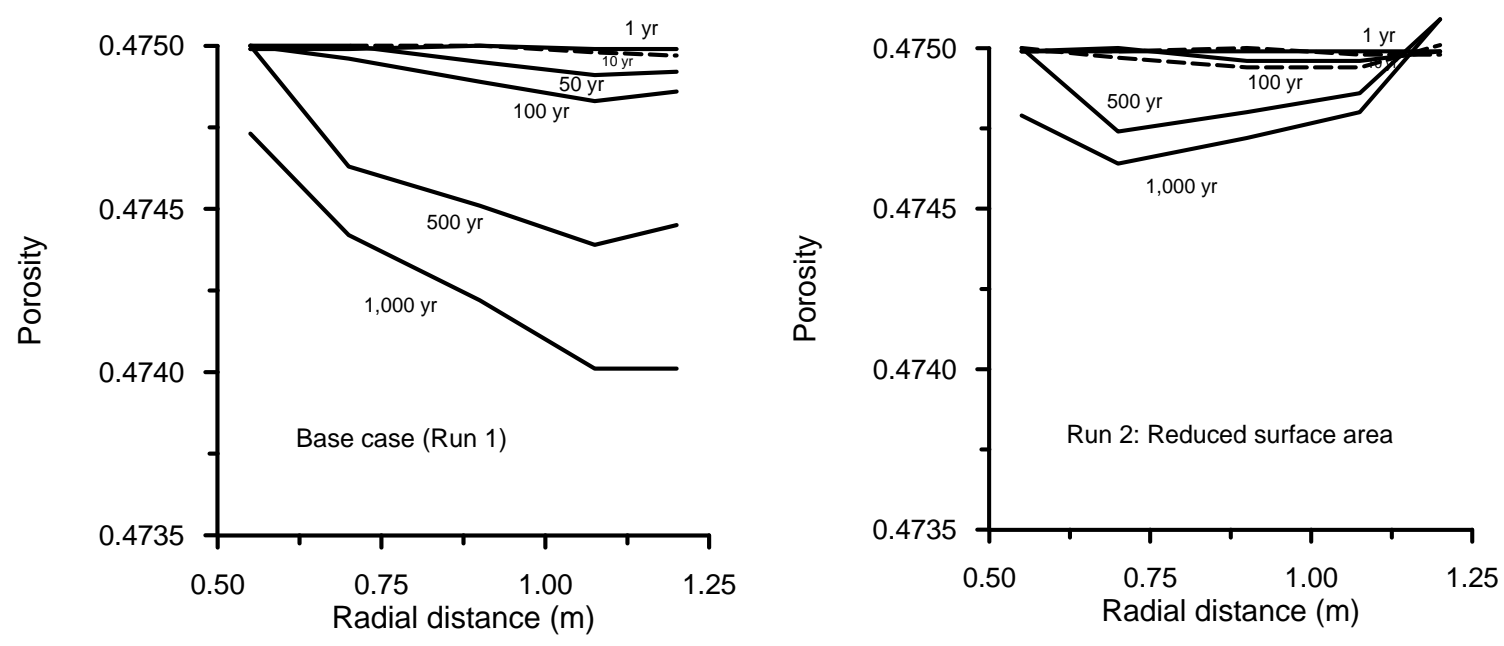

(a)

(b)

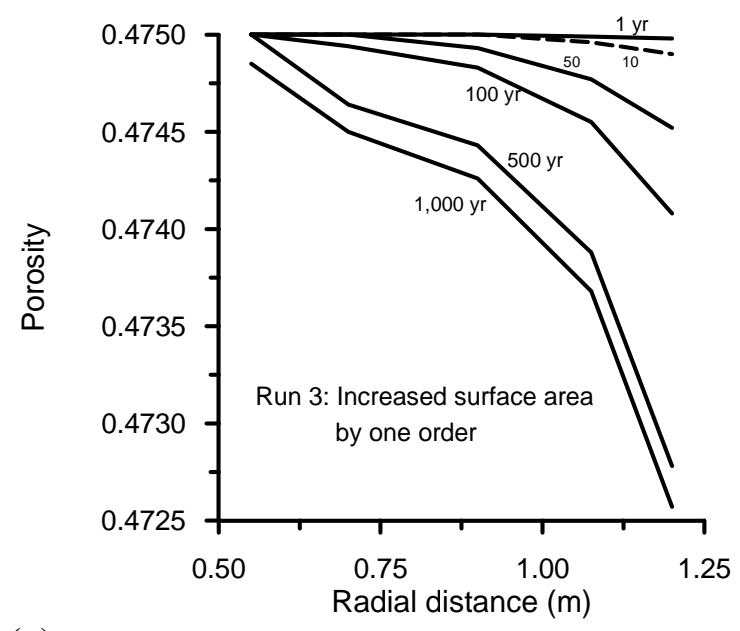

(c)

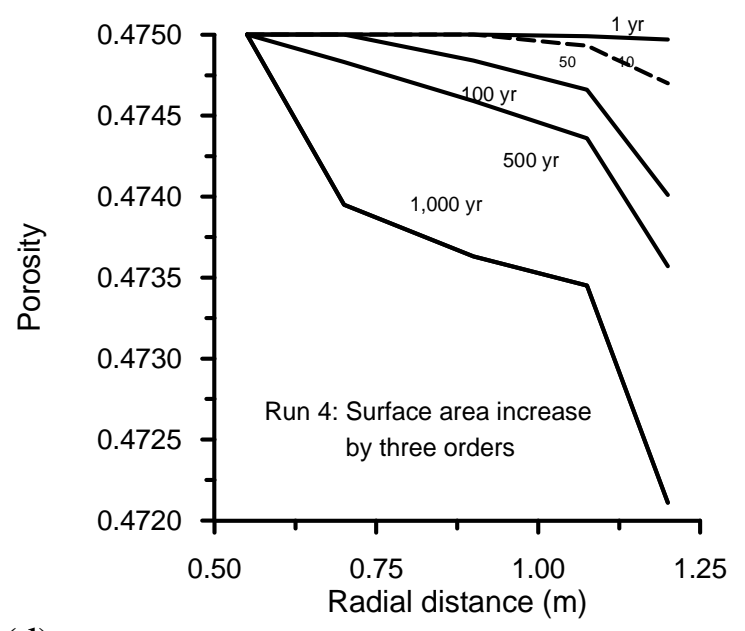

(d)

Fig. 3. Distribution of porosity in bentonite buffer: (a) base case, (b) reactive surface area decreased by one order of magnitude, (c) reactive surface area increased by one order of magnitude, and (d) reactive surface area increased by three orders of magnitude. 

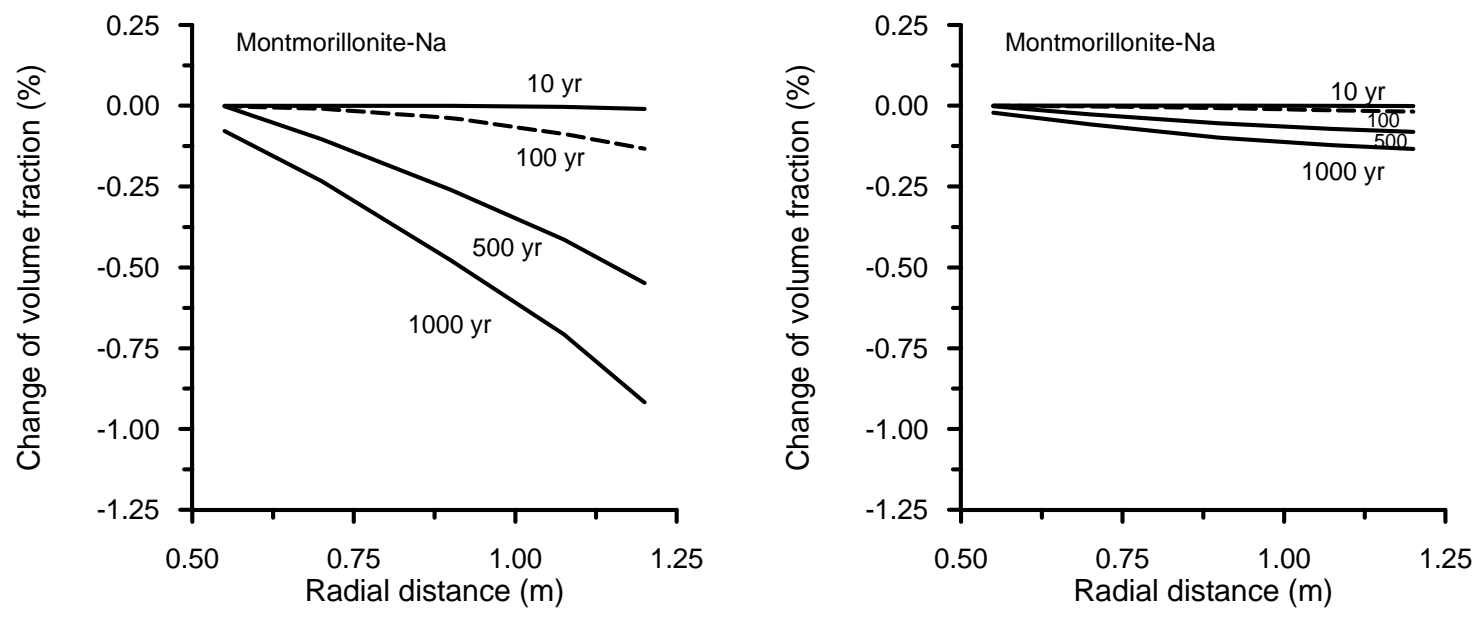

(a)

(b)

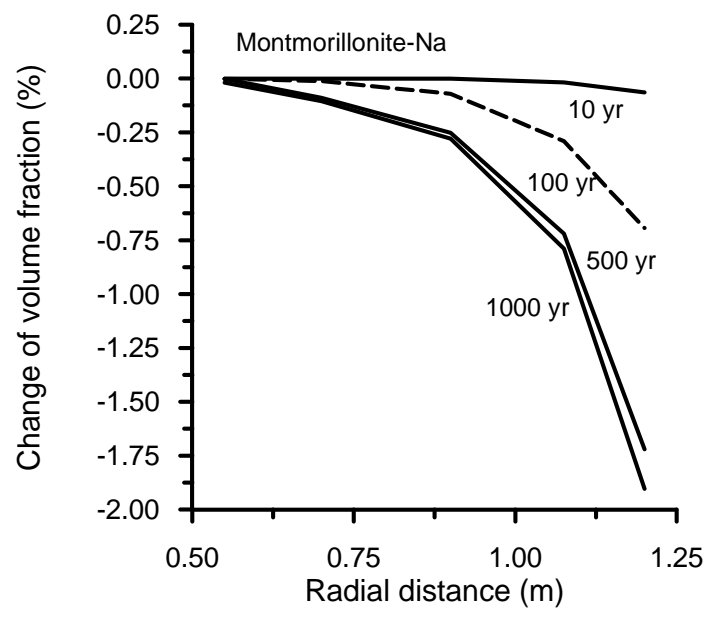

(c)

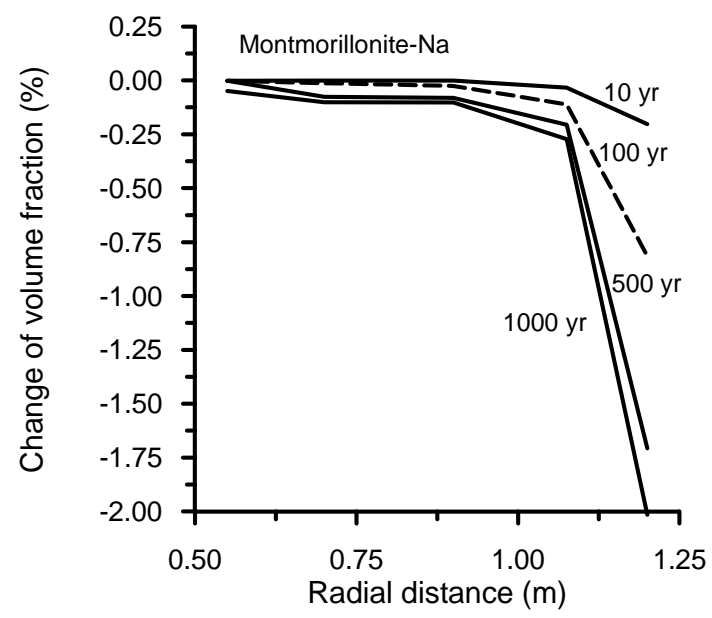

(d)

Fig. 4. Changes in volume fraction of montmorillonite-Na (negative values indicate dissolution, positive precipitation) in bentonite buffer: (a) base case, (b) reactive surface area decreased by one order of magnitude, (c) reactive surface area increased by one order of magnitude, and (d) reactive surface area increased by three orders of magnitude. 

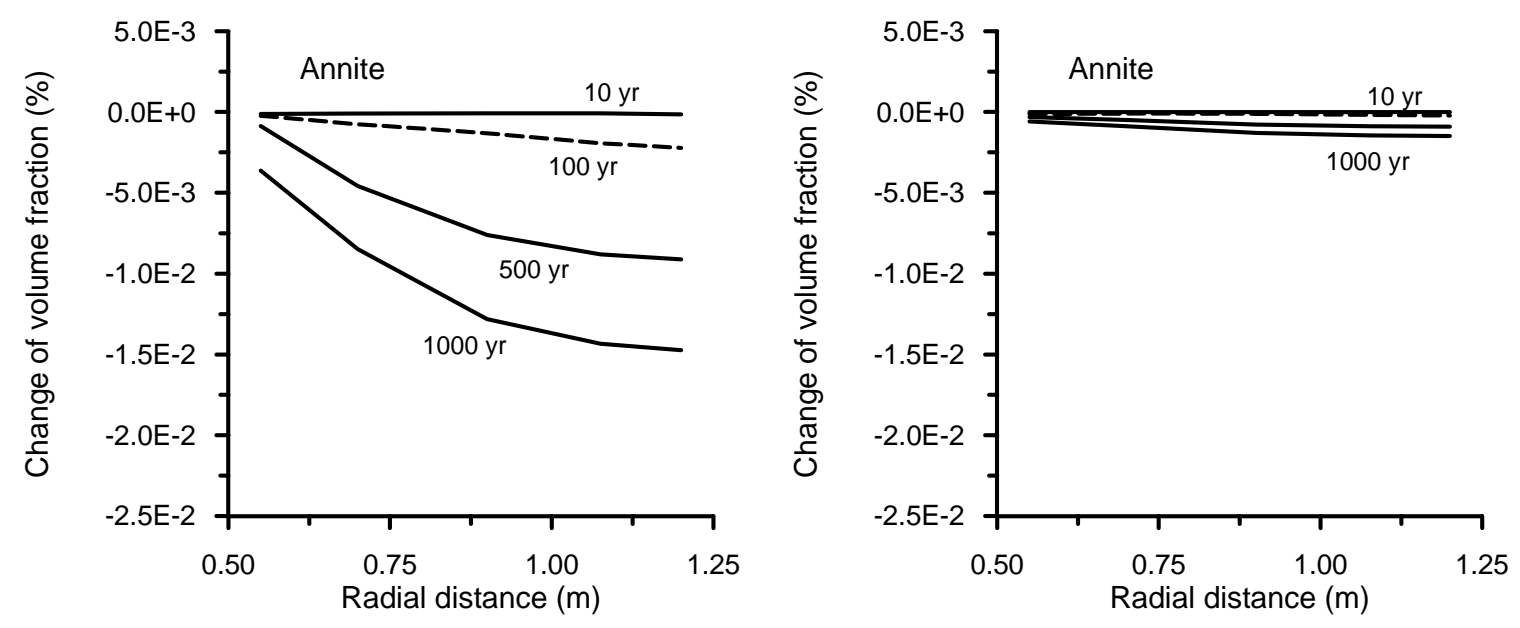

(a)

(b)
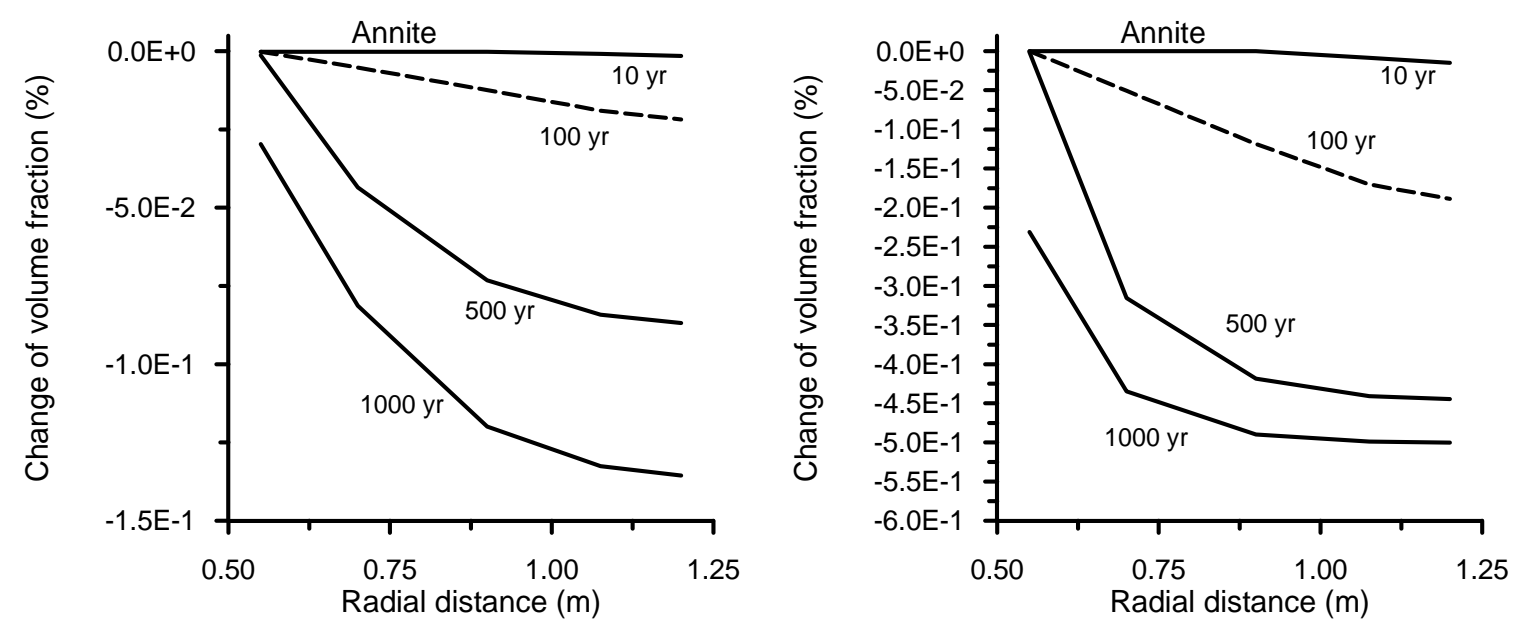

(c)

(d)

Fig. 5. Change in volume fraction of annite in bentonite buffer: (a) base case, (b) reactive surface area decreased by one order of magnitude, (c) reactive surface area increased by one order of magnitude, and (d) reactive surface area increased by three orders of magnitude. 

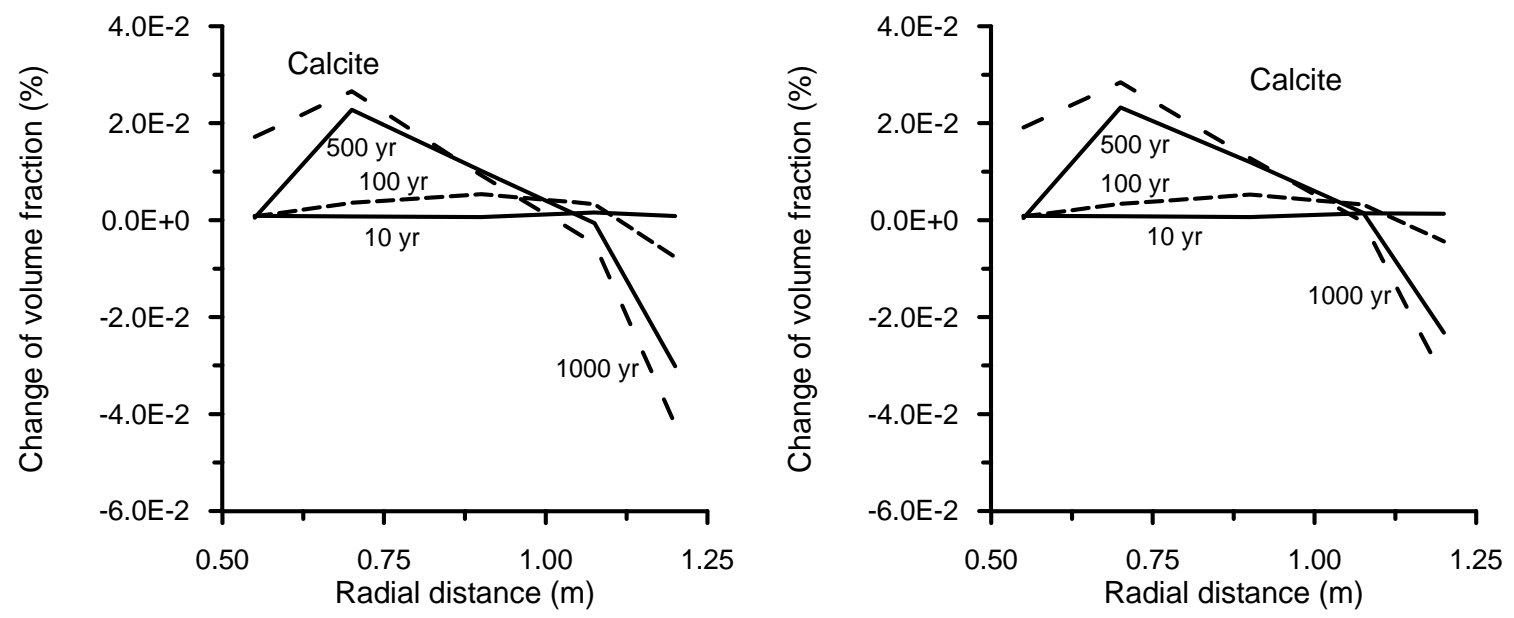

(a)

(b)
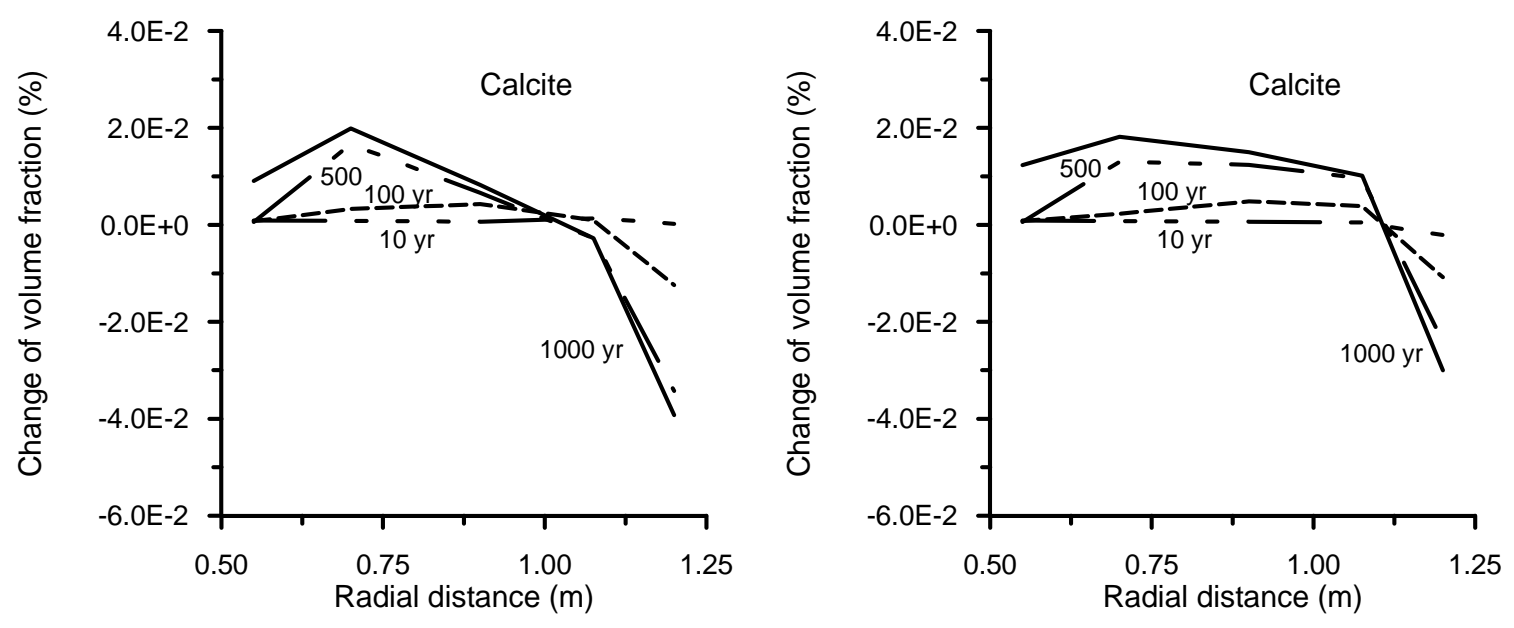

(c)

(d)

Fig. 6. Change in volume fraction of calcite in bentonite buffer: (a) base case, (b) reactive surface area decreased by one order of magnitude, (c) reactive surface area increased by one order of magnitude, and (d) reactive surface area increased by three orders of magnitude. 

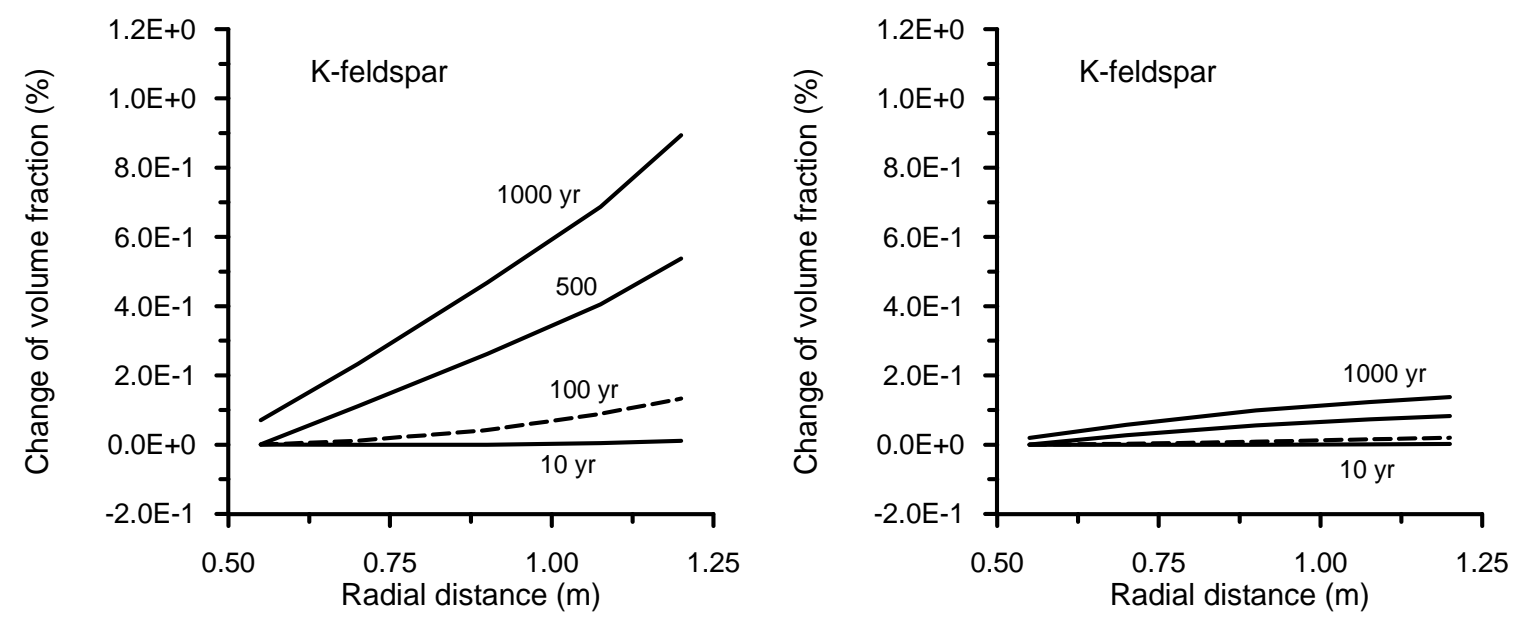

(a)

(b)
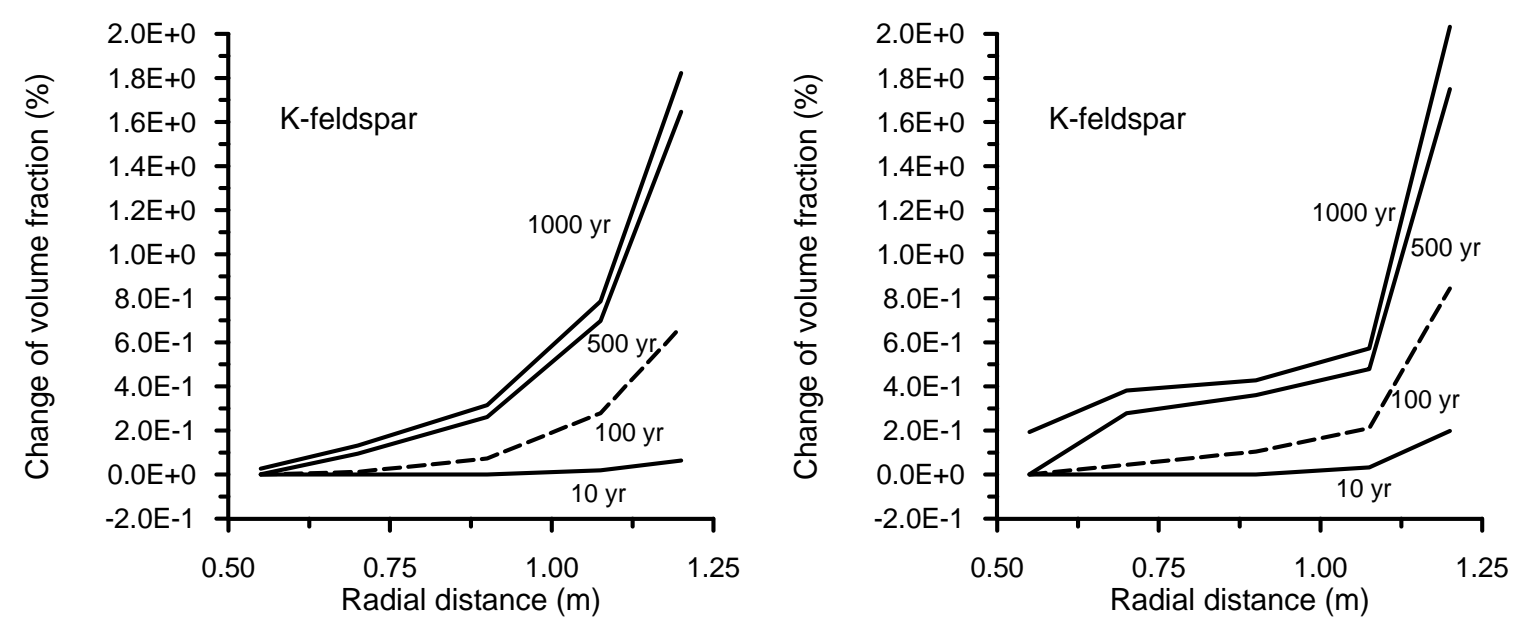

(c)

(d)

Fig. 7. Change in volume fraction of K-feldspar in bentonite buffe: (a) base case, (b) reactive surface area decreased by one order of magnitude, (c) reactive surface area increased by one order of magnitude, and (d) reactive surface area increased by three orders of magnitude. 

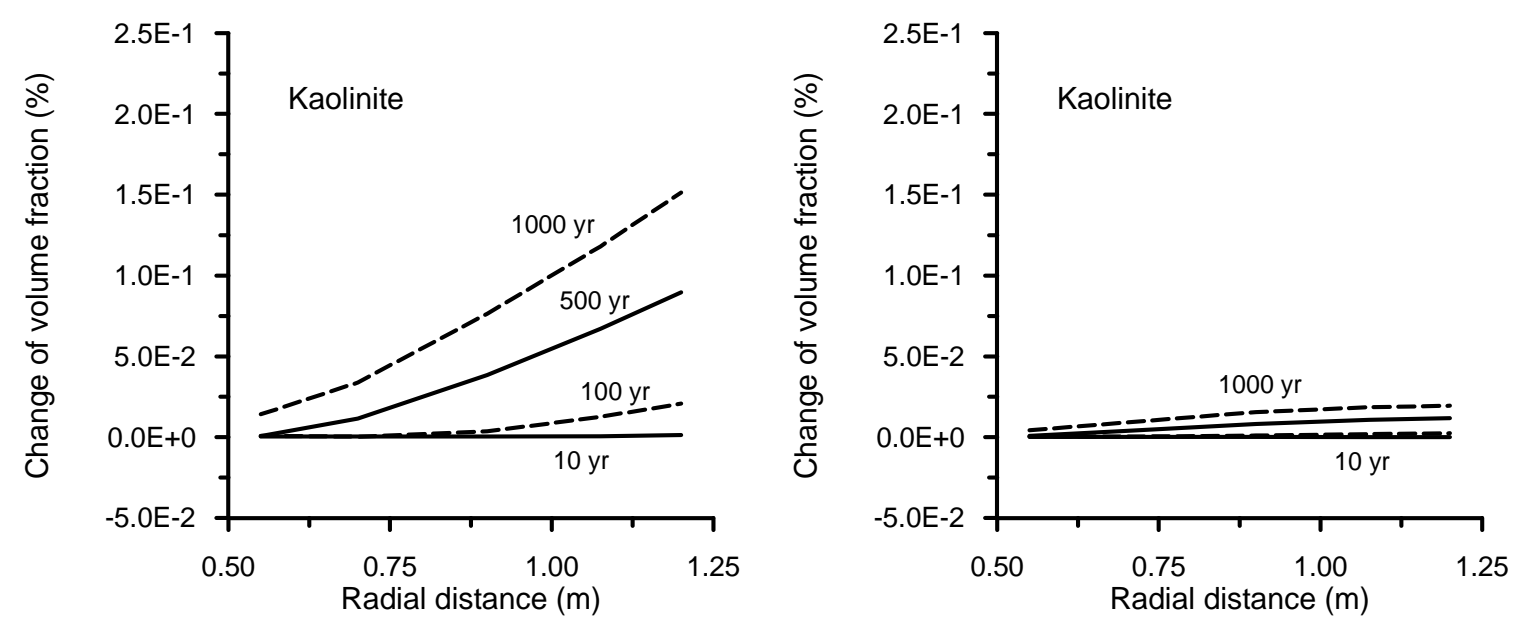

(a)

(b)
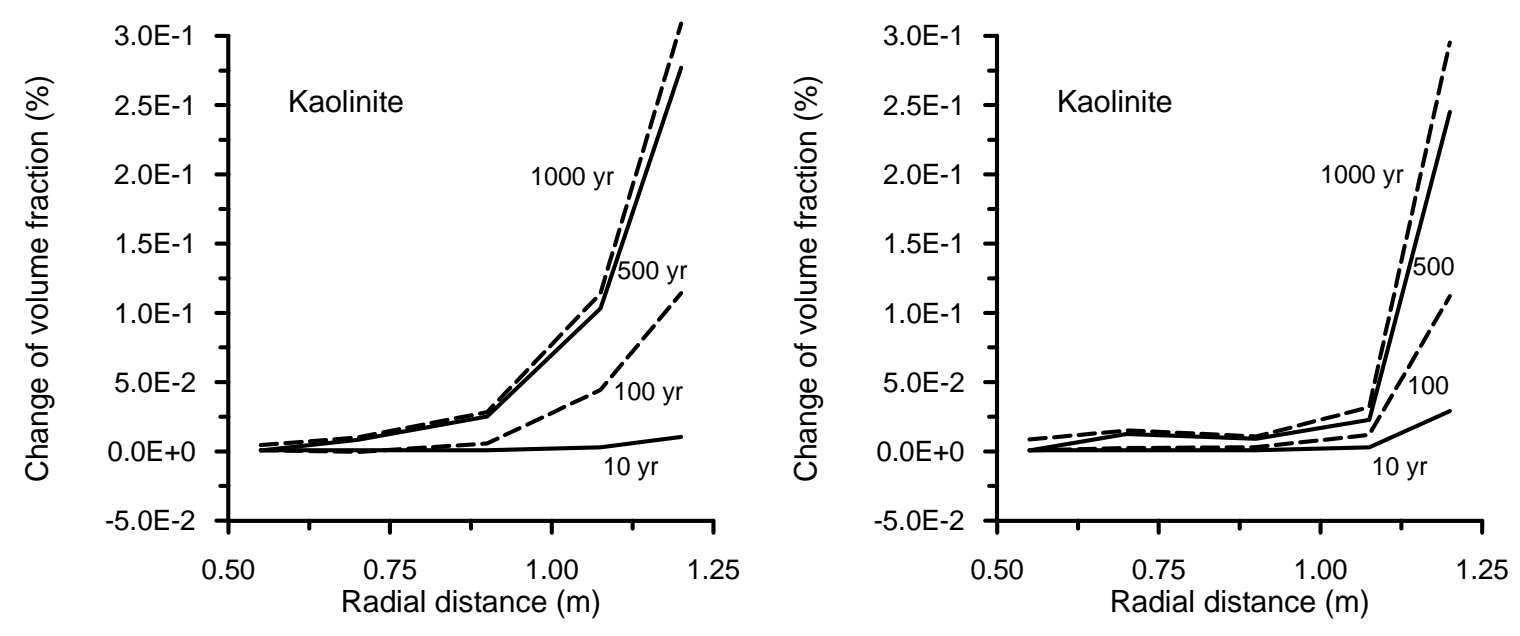

(c)

(d)

Fig. 8. Change in volume fraction of kaolinite in bentonite buffer: (a) base case, (b) reactive surface area decreased by one order of magnitude, (c) reactive surface area increased by one order of magnitude, and (d) reactive surface area increased by three orders of magnitude. 

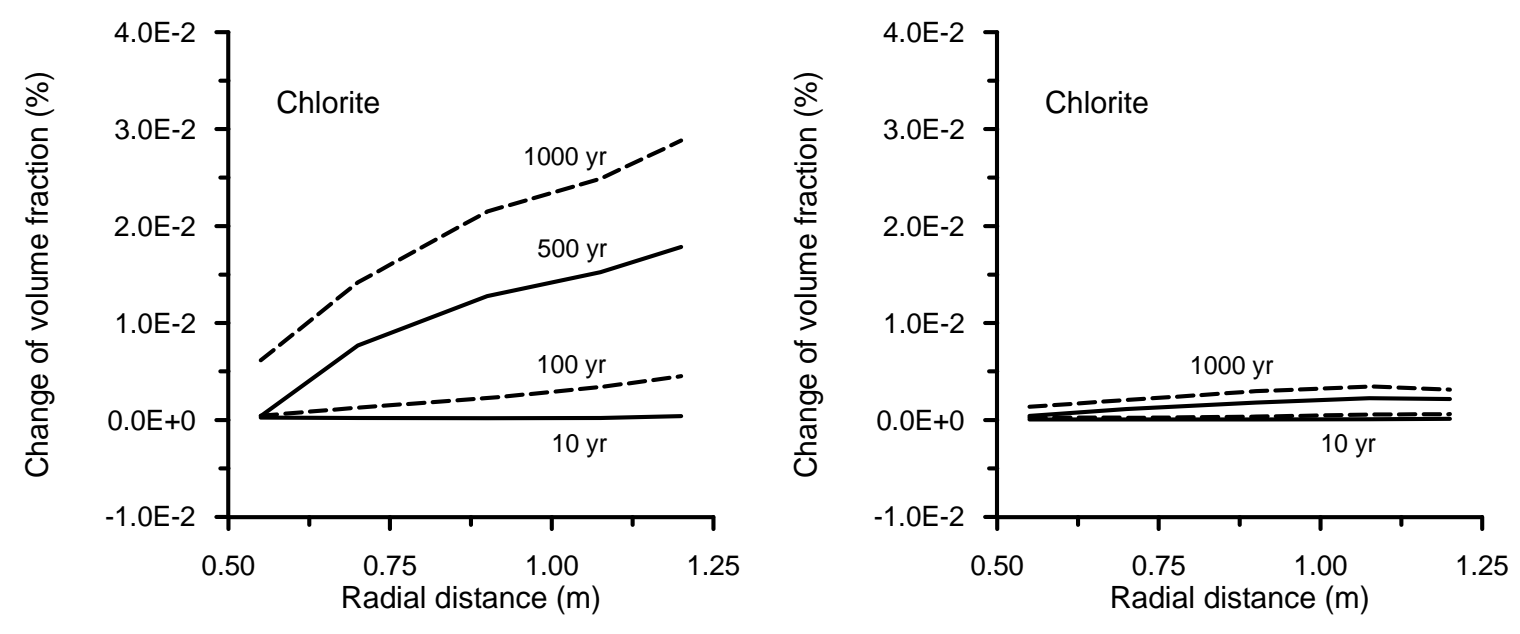

(a)

(b)

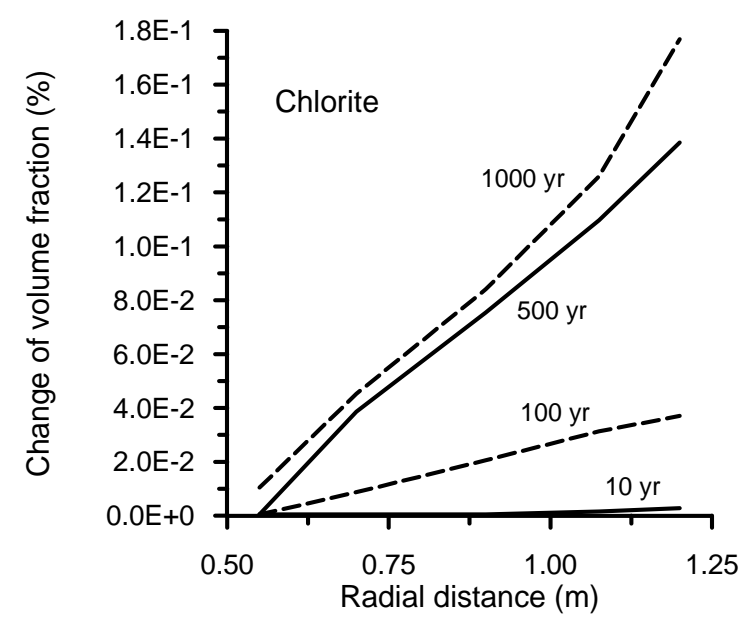

(c)

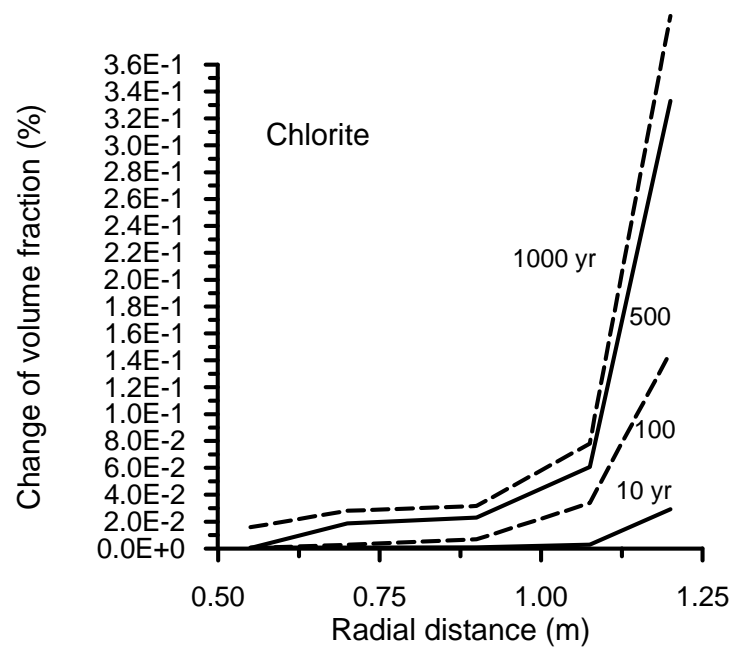

(d)

Fig. 9. Change in volume fraction of chlorite in bentonite buffer: (a) base case, (b) reactive surface area decreased by one order of magnitude, (c) reactive surface area increased by one order of magnitude, and (d) reactive surface area increased by three orders of magnitude. 


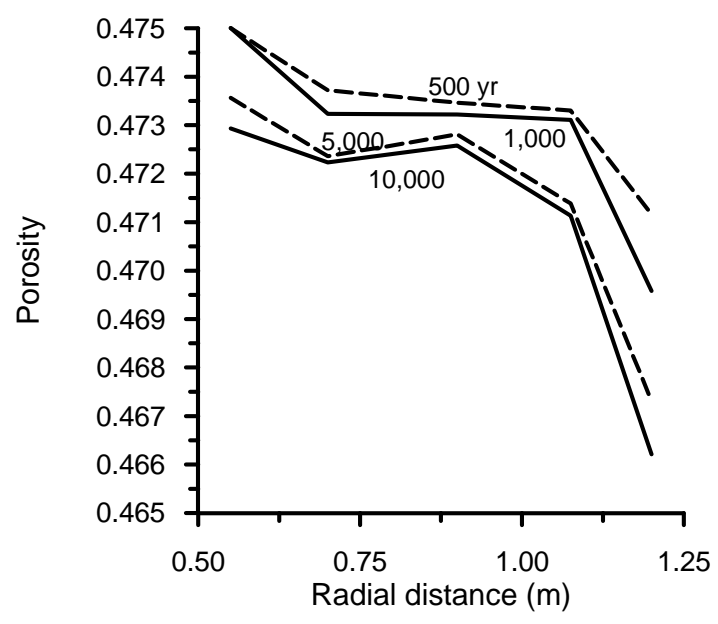

Fig. 10. Changes in porosity obtained for a simulation period of 10,000 years (for the case of decay heat falling off much more slowly). 


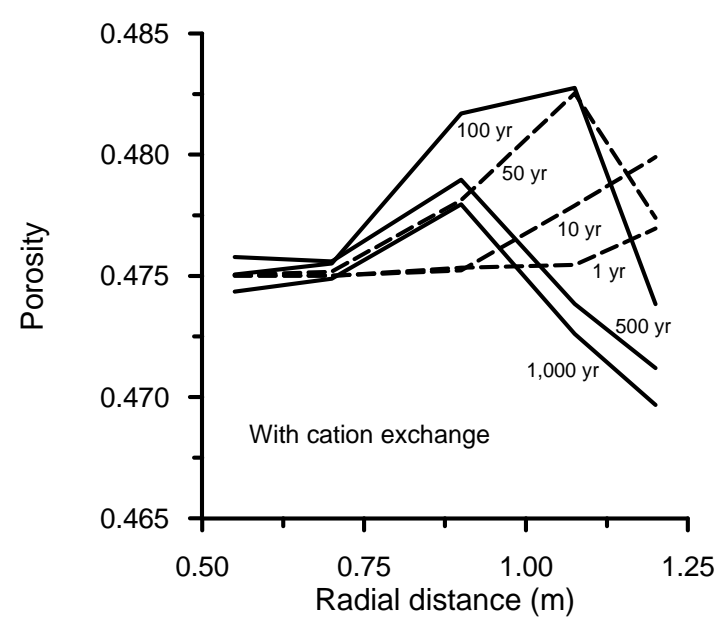

Fig. 11. Changes in porosity obtained for a simulation case considering cation exchange. 
Table 1. Thermo-physical parameters used for bentonite and Opalinus clay in the THC model.

\begin{tabular}{|l|c|c|}
\hline & Bentonite & Opalinus Clay \\
\hline Porosity $\phi[-]$ & 0.475 & 0.14 \\
\hline Permeability $k\left[\mathrm{~m}^{2}\right]$ & $1 \times 10^{-19}$ & $1 \times 10^{-20}$ \\
\hline Pore compressibility $\left(c_{\phi}\right)\left[\mathrm{Pa}^{-1}\right]$ & $3.58 \times 10^{-9}$ & $1.83 \times 10^{-9}$ \\
\hline Rock grain density $\rho_{R}\left(\mathrm{~kg} / \mathrm{m}^{3}\right)$ & 2700 & 2670 \\
\hline Rock specific heat $C_{R}\left(\mathrm{~J} / \mathrm{kg} /{ }^{\circ} \mathrm{C}\right)$ & 964 & 946.5 \\
\hline Thermal conductivity $\lambda\left(\mathrm{W} / \mathrm{m} /{ }^{\circ} \mathrm{C}\right)$ & 1.35 & 2.5 \\
\hline Two-Phase Constitutive $\mathrm{Model}$ & van Genuchten & van Genuchten \\
\hline Residual liquid saturation $S_{l r}[-]$ & 0.3 & 0.5 \\
\hline Residual gas saturation $S_{g r}[-]$ & 0.02 & 0.02 \\
\hline van Genuchten parameter $n[-]$ & 1.82 & 1.67 \\
\hline Capillary strength pressure $1 / \alpha[\mathrm{Pa}]$ & $1.8 \times 10^{7}$ & $1.8 \times 10^{7}$ \\
\hline
\end{tabular}


Table 2. Initial mineral volume fractions and possible secondary mineral phases (with a zero volume percentage) used in the simulations.

\begin{tabular}{|l|l|l|}
\hline \multirow{2}{*}{ Mineral } & \multicolumn{2}{|c|}{ Volume percent in term of solid } \\
\cline { 2 - 3 } & Bentonite & Opalinus clay \\
\hline Calcite & 1.4 & 15.0 \\
\hline Quartz & 15.1 & 18.0 \\
\hline Kaolinite & 1.0 & 10.0 \\
\hline Illite & & 20.0 \\
\hline K-feldspar & 6.5 & 3.0 \\
\hline Montmorillonite-Na & 75 & 10.0 \\
\hline Montmorillonite-Ca & & 10.0 \\
\hline Chlorite & & 10.0 \\
\hline Dolomite & & 1.0 \\
\hline Siderite & & 3.0 \\
\hline Ankerite & & 1.0 \\
\hline Annite & 1.0 & \\
\hline Anhydrite & & \\
\hline Amorphous silica & & \\
\hline
\end{tabular}


Table 3. Parameters for calculating kinetic rate constants of minerals. Note that (1) all rate constants are listed for dissolution; (2) $A$ is specific surface area, $k^{25}$ is kinetic constant at $25^{\circ} \mathrm{C}, E$ is activation energy, and $n$ is the power term (Eq. 3); (3) the power terms $n$ for both acid and base mechanisms are with respect to $\mathrm{H}^{+}$.

\begin{tabular}{|c|c|c|c|c|c|c|c|c|c|}
\hline \multirow[t]{3}{*}{ Mineral } & \multirow{3}{*}{$\begin{array}{l}A \\
\left(\mathrm{~cm}^{2} / \mathrm{g}\right)\end{array}$} & \multicolumn{8}{|c|}{ Parameters for kinetic rate law } \\
\hline & & \multicolumn{2}{|c|}{ Neutral mechanism } & \multicolumn{3}{|c|}{ Acid mechanism } & \multicolumn{3}{|c|}{ Base mechanism } \\
\hline & & $\begin{array}{l}k^{25} \\
\left(\mathrm{~mol} / \mathrm{m}^{2} / \mathrm{s}\right)\end{array}$ & $\begin{array}{l}E \\
(K J \\
/ m o l)\end{array}$ & $k^{25}$ & $E$ & $n\left(H^{+}\right)$ & $k^{25}$ & $E$ & $n\left(H^{+}\right)$ \\
\hline Calcite & \multicolumn{9}{|c|}{ Equilibrium } \\
\hline Quartz & 98 & $1.023 \times 10^{-14}$ & 87.7 & & & & & & \\
\hline Kaolinite & 1516 & $6.918 \times 10^{-14}$ & 22.2 & $4.898 \times 10^{-12}$ & 65.9 & 0.777 & $8.913 \times 10^{-18}$ & 17.9 & -0.472 \\
\hline Illite & 1516 & $1.660 \times 10^{-13}$ & 35 & $1.047 \times 10^{-11}$ & 23.6 & 0.34 & $3.020 \times 10^{-17}$ & 58.9 & -0.4 \\
\hline K-feldspar & 98 & $3.890 \times 10^{-13}$ & 38 & $8.710 \times 10^{-11}$ & 51.7 & 0.5 & $6.310 \times 10^{-12}$ & 94.1 & -0.823 \\
\hline $\begin{array}{l}\text { Montmorillon-ite- } \\
\mathrm{Na}\end{array}$ & 1516 & $1.660 \times 10^{-13}$ & 35 & $1.047 \times 10^{-11}$ & 23.6 & 0.34 & $3.020 \times 10^{-17}$ & 58.9 & -0.4 \\
\hline $\begin{array}{l}\text { Montmorillon-ite- } \\
\text { Ca }\end{array}$ & 1516 & $1.660 \times 10^{-13}$ & 35 & $1.047 \times 10^{-11}$ & 23.6 & 0.34 & $3.020 \times 10^{-17}$ & 58.9 & -0.4 \\
\hline Chlorite & 1516 & $3.02 \times 10^{-13}$ & 88 & $7.762 \times 10^{-12}$ & 88 & 0.5 & & & \\
\hline Dolomite & 98 & $2.951 \times 10^{-8}$ & 52.2 & $6.457 \times 10^{-4}$ & 36.1 & 0.5 & & & \\
\hline Siderite & 98 & $1.260 \times 10^{-9}$ & 62.76 & $6.457 \times 10^{-4}$ & 36.1 & 0.5 & & & \\
\hline Ankerite & 98 & $1.260 \times 10^{-9}$ & 62.76 & $6.457 \times 10^{-4}$ & 36.1 & 0.5 & & & \\
\hline Annite & 98 & $2.818 \times 10^{-14}$ & 22.0 & $1.413 \times 10^{-12}$ & 22.0 & 0.37 & $2.818 \times 10^{-15}$ & 22.0 & -0.22 \\
\hline Anhydrite & \multicolumn{9}{|c|}{ Equilibrium } \\
\hline Amorphous silica & 98 & $3.000 \times 10^{-10}$ & 49.8 & & & & & & \\
\hline
\end{tabular}


Table 4. List of cation exchange reactions considered for the THC modeling (' $X$ ' represents cation exchange sites).

\begin{tabular}{ll}
\hline Cation exchange: & Selectivity (in terms of $\mathrm{Na}^{+}$) \\
\hline $\mathrm{Na}^{+}+0.5 \mathrm{Ca}-\mathrm{X}_{2}=0.5 \mathrm{Ca}^{2+}+\mathrm{Na}-\mathrm{X}$ & 0.69 \\
$\mathrm{Na}^{+}+0.5 \mathrm{Mg}-\mathrm{X}_{2}=0.5 \mathrm{Mg}^{2+}+\mathrm{Na}-\mathrm{X}$ & 0.67 \\
$\mathrm{Na}^{+}+\mathrm{K}-\mathrm{X}=\mathrm{K}^{+}+\mathrm{Na}-\mathrm{X}$ & 0.42 \\
$\mathrm{Na}^{+}+\mathrm{H}-\mathrm{X}=\mathrm{H}^{+}+\mathrm{Na}-\mathrm{X}$ & 1.88 \\
\hline
\end{tabular}

